\title{
Effectiveness of Social Support in Coping with Stroke by Medically Ill Patient in Ibadan
}

\author{
Mainoo Blessing and Oyinlola Oluwagbemiga* \\ Medical Social Services Department, University College Hospital, Ibadan, Nigeria
}

\begin{abstract}
Stroke, also known as cerebrovascular accident (CVA), cerebrovascular insult (CVI) or brain attack, is when poor blood flow to the brain results in cell death, there is need for concurrent coping with stroke demand cognitive effort from the patient. Social support intervention is best started as early (at diagnosis) and demands continuous effort. Hence, the study examines the effectiveness of social support in coping with stroke by medically ill patient in Ibadan.

The study is a descriptive survey research and a total of 50 stroke patients attending the government hospital of Adeoyo, Ibadan were purposively selected for the study. The study adopted the researchers, Multidimensional Scale of Social Support and the result yielded $r=0.78$ while coping with stroke was measured using a scale from Journal compilation (2008) Blackwell publishing Ltd. titled stroke self-efficacy questionnaire, the result yielded 0.81 . The study developed five hypotheses and pearson product moment correlation was used to analyze of the findings.

The result revealed that, there was a significant effect of family support on coping with stroke by the medically ill patients $(r=0.352, N=50, p<0.05)$, there was a significant effect of financial support on coping with stroke by the medically ill patients $(r=0.658, N=50, p<0.05)$, there was a significant relationship of emotional support on coping with stroke by the medically ill patients $(r=0.402, N=50, p<0.05)$, there was a significant effect of companionship support on coping with stroke by the medically ill patients $(r=0.654, N=50, p<0.05)$, the multiple regression analysis showed that, Family Support $(\beta=-0.391, p<0.05)$ had significant effect followed by Financial Support $(\beta=0.418, p<0.05)$, followed by Emotional Support $(\beta=0.165, p<0.05)$ and Companionship Support $(\beta=0.7878, p<0.05)$ Hence, the study revealed that, living with stroke requires joint effort of family support, financial support, emotional support and companionship support to help make the necessary changes to cope and adapt to stroke.

The study recommended that, Social support from family members and caregivers especially to patients suffering from stroke is of great importance to improve their health. Family and care givers of stroke patients should always remember that low social support has a negative response to the health stroke patients. It is also recommended that care givers should be optimistic seeing the brighter side of patient's life. The medical social workers, nurses and other health care givers should improve their scope of knowledge and skills to have a greater understanding of how personal factors impact the health of medically ill patients suffering from stroke.
\end{abstract}

Keywords: Stroke; Social support; Coping; Medically ill; Patient

\section{Introduction}

Stroke, also known as cerebrovascular accident (CVA), cerebrovascular insult (CVI) or brain attack, is when poor blood flow to the brain results in cell death. In the 1970s the World Health Organization defined stroke as a "neurological deficit of cerebrovascular cause that persists beyond $24 \mathrm{~h}$ or is interrupted by death within 24 h" [1] although the word "stroke" is centuries old. This definition was supposed to reflect the reversibility of tissue damage and was devised for the purpose, with the time frame of $24 \mathrm{~h}$ being chosen arbitrarily. The 24 $\mathrm{h}$ limit divides stroke from transient ischemic attack, which is a related syndrome of stroke symptoms that resolve completely within $24 \mathrm{~h} \mathrm{[1].}$ With the availability of treatments which can reduce stroke severity when given early, many now prefer alternative terminology, such as brain attack and acute ischemic cerebrovascular syndrome (modelled after heart attack and acute coronary syndrome, respectively), to reflect the urgency of stroke symptoms and the need to act swiftly [2].

Stroke without an obvious explanation is termed "cryptogenic" (of unknown origin); this constitutes $30-40 \%$ of all ischemic strokes [3]. There are various classification systems for acute ischemic stroke. The Oxford Community Stroke Project classification (OCSP, also known as the Bamford or Oxford classification) relies primarily on the initial symptoms; based on the extent of the symptoms, the stroke episode is classified as total anterior circulation infarct (TACI), partial anterior circulation infarct (PACI), lacunar infarct (LACI) or posterior circulation infarct (POCI). These four entities predict the extent of the stroke, the area of the brain that is affected, the underlying cause and the prognosis [4]. The TOAST (Trial of Org 10172 in Acute Stroke Treatment) classification is based on clinical symptoms as well as results of further investigations; on this basis, a stroke is classified as being due to: Embolism due to atherosclerosis of a large artery, An embolism originating in the heart, Complete blockage of a small blood vessel, Other determined cause, Undetermined cause (two possible causes, no cause identified or incomplete investigation) [4]. Users of stimulant drugs such as cocaine and methamphetamine are at a high risk for ischemic strokes [5]. In 2013 approximately 6.9 million people had an ischemic stroke and 3.4 million people had a haemorrhagic stroke. In 2010 there were about 33 million people who had previously had a stroke and were still alive. Between 1990 and 2010 the number of strokes which occurred each year decreased by approximately $10 \%$ in the developed world and increased by $10 \%$ in the developing world. In 2013, stroke was the second most frequent cause of death after coronary artery disease, accounting for 6.4 million deaths (12\% of the total) [6].

*Corresponding author: Oyinlola Oluwagbemiga, Medical Social Services Department, University College Hospital, Ibadan, Nigeria, Tel: +2347030272125; E-mail: gsticks2@gmail.com

Received July 20, 2017; Accepted August 01, 2017; Published August 08, 2017

Citation: Blessing M, Oluwagbemiga O (2017) Effectiveness of Social Support in Coping with Stroke by Medically III Patient in Ibadan. Int J Neurorehabilitation 4 281. doi: $10.4172 / 2376-0281.1000281$

Copyright: () 2017 Blessing M, et al. This is an open-access article distributed under the terms of the Creative Commons Attribution License, which permits unrestricted use, distribution, and reproduction in any medium, provided the original author and source are credited. 
Stroke can affect people physically, mentally, emotionally, or a combination of the three. The results of stroke vary widely depending on size and location of the lesion [7]. Emotional problems following a stroke can be due to direct damage to emotional centers in the brain or from frustration and difficulty adapting to new limitations. Post-stroke emotional difficulties include anxiety, panic attacks, flat affect (failure to express emotions), mania, apathy and psychosis. Other difficulties may include a decreased ability to communicate emotions through facial expression, body language and voice [8]. Disruption in self-identity, relationships with others and emotional well-being can lead to social consequences after stroke due to the lack of ability to communicate. Many people who experience communication impairments after a stroke find it more difficult to cope with the social issues rather than physical impairments. Broader aspects of care must address the emotional impact speech impairment has on those who experience difficulties with speech after a stroke $[9,10]$.

Social support has been found to help patients cope with their conditions and adhere to various aspects of treatment [11]. Stroke is one of the most common disease conditions globally. In Nigeria, it is the most frequent cause of neurologic admissions [12]. In addition, stroke is the largest cause of complex disability in adults and $50-75 \%$ of stroke survivors are reported to experience varying degrees of disability [12]. Participation restriction and impaired quality of life are also prominent features of the stroke sequelae [13] while a growing body of evidence indicates that suffering a stroke increases the risk of suicide and suicide ideation [14]. Given the negative consequences of stroke, several studies have explored factors that modulate stroke outcomes. One of such factors that have been identified is social support. Social support from family, friends and community has been shown to provide protection against poor psychosocial and functional outcomes after stroke [15]. The mediating role of social support between functional ability and post-stroke depression and post-stroke quality of life has also been identified with social support regarded as an intervening variable in stroke outcomes [16]. Furthermore, social support in the form of emotional support may promote cognitive resilience [16] and prevent depression [17] after stroke.

Enhancing social support could, therefore serve as an important strategy for reducing or preventing psychiatric distress and warding off post-stroke depression and improving the quality of life of stroke survivors $[18,19]$. Designing appropriate social support enhancing interventions may require information on factors that influence the availability of the support. The innate sociability of humans plays a role in every moment of a person's life. Accordingly, social support is the key to many human accomplishments, including the successful management of stress. Social support is the perception or reality that one is cared for, has assistance from others and is a member of a supportive social network. Social support is so important that social isolation can lead to depression, anxiety and other negative emotions. In fact, feelings of social isolation are one of the primary triggers of suicide. Supportive resources can be emotional, financial, informational and companion-based.

The term "social coping" refers to a person seeking social support while under stress. Emotional support is the presence, warmth and nurturance that provide the individual with a sense of value, esteem, acceptance, or affection. Financial support, that provides concrete assistance to patient suffering from stroke. Informational support is the provision of advice, guidance or suggestion that enables individual problem-solving. Companionship support is the presence of care givers that provides support. Hence, social support plays a major role in successful coping with stroke; social support reduces psychological distress and promotes adjustments that counteract high stress levels. People with low amounts of social support report higher instances of depression, anxiety and mental disorders. For these people, stressful situations create higher amounts of panic, phobia and disorder than for those with high social support. Stroke patients experience social problems, such as anxiety, depression, social isolation, loneliness, helplessness and hopelessness. All of these social problems can increase patients' need for holistic care, including attention to the person's environment and receiving support from caregivers. If patients suffering from stroke are better supported and cared for, these negative consequences might be prevented or at least decreasedHence, this study examine the effectiveness of social support in coping with stroke by the medically ill patients in Ibadan

\section{Purpose of the Study}

The general purpose of the study is to examine the effectiveness of social support in coping with stroke by medically ill patients in Ibadan.

The general purpose of the study is to:

1. Determine how financial support help patients to cope with stroke.

2. Find out how effective is family support in helping patients to cope with stroke.

3. Find out how emotional supports affect the coping ability of the patients with stroke.

4. Determine how level of companionship affect the coping ability of the patients with stroke.

\section{Research Hypotheses}

\section{Hypothesis one}

There is no significant effect of family support on coping with stroke by medically ill patients.

\section{Hypothesis two}

There is no significant effect of financial support on coping with stroke by medically ill patients.

\section{Hypothesis three}

There is no significant effect of emotional support on coping with stroke by medically ill patients.

\section{Hypothesis four}

There is no significant effect of companionship support on coping with stroke by medically ill patients.

\section{Hypothesis five}

There is no significant joint effect of the independent variables (Family Support, Financial Support, Emotional Support and Companionship Support) on Coping with Stroke by the medically ill patient.

\section{Methodology}

\section{Study design}

This is a descriptive survey design was adopted for this study. The major population of the study includes all consenting patients seeking treatment for stroke at the government hospital, Adeoyo, Ibadan. 


\section{Sample and sampling technique}

The study purposively sampled a total of 50 patients (in and out patients) who were selected as sample for the study. They were made up of 30 male and 20 female patients who have consented to participate in the study at the government hospital, Adeoyo, Ibadan.

\section{Research instrument}

The main tool of data collection for this study is a single questionnaire, tagged "Social support and coping with Stroke Questionnaire (SSACWSQ). The questionnaire is made up of 34 items divided into three sections A, B and C respectively. Section A contains 9 items measuring demographic variables of the respondents. Section $B$ contains 25 items measuring level of social support (financial support, emotional support, family support and companionship) received by the stroke patients. The items were adopted from Social support questionnaire. It yielded a Cronbach alpha value of 0.80 . The last section contains 5 items measuring level of patients coping with stroke. The items were adopted from Journal compilation (2008) Blackwell publishing Ltd.s stroke self-efficacy questionnaire. It yielded an alpha value of 0.81 .

\section{Procedure of data collection}

The researcher obtained ethical approval from the Government Hospital, Adeoyo, Ibadan to seek their permission to conduct the study among Stroke Patients. Also the researcher and his research assistants sought the consent of the respondents to answer the questions contained in the instrument. The impersonal nature of the questionnaire provided for a complete anonymity. The questionnaires were administered to respondents (patients having stroke), from Adeoyo state Hospital Ibadan. Out of the 50 questionnaires, 5 were not properly completed and therefore rejected. The remaining 45 copies that were properly completed were used for final analysis.

\section{Data analysis}

Data collected were analyzed using descriptive statistical analysis of frequency counts and sample percentages for the respondents' characteristics, while Pearson Product Moment Correlation was used for data analysis.

\section{Results}

\section{Analysis of demographic characteristics of the respondents}

The following presents the demographic characteristics of the respondents in terms of gender, religion, level of education, etc.

Based on the Table 1 presented above which revealed that, male respondents are 29 (58.0\%) while their female counterparts are 21 (42.0\%). Christians are 29 (58.0\%), the Muslims are 20 (40.0\%) while the Traditional Worshiper was 1 (2.0). 4 (8.0\%) of the respondents had no formal education; 18 (36.0\%) had Primary education; 20 (40.0\%) had Secondary education; 7 (14.0\%) had Tertiary education; $10(20.0 \%)$ had other educational certificates. $8(16.0 \%)$ of the respondents are Farmers, 19 (38.0\%) are Petty Traders, 2 (4.0\%) are Artisans, 7 (14.0\%) are Civil Servants, $5(10.0 \%)$ are Teachers, $6(12.0 \%)$ are Pensioners and (\%) are in other occupations respectively. 7 (14.0\%) of the respondents earned N5,000, 3 (6.0\%) earned N6,000-N10,000, 2 (4.0\%) earned $\mathrm{N} 11,000-\mathrm{N} 15,000,10$ (20.0\%) earned N16,000-20,000, 27 (54.0\%) earned $\mathrm{N} 21,000-\mathrm{N} 30,000$ and 1 (2.0\%) earned N31,000-N40,000, respectively. $44(88.0 \%)$ of the respondents are Yorubas, 5 (10.0\%) were Igbos and $1(2.0 \%)$ was from Niger-Delta.

\section{Testing of research hypotheses}

Hypothesis one: There is no significant effect of family support on coping with stroke by the medically ill patients (Table 2).

Pearson Product Moment Correlation was used to determine the relationship between family support and coping with stroke by the medically ill patients. The result shows that there was a significant effect of family support on coping with stroke by the medically ill patients $(\mathrm{r}=0.352, \mathrm{~N}=50, \mathrm{p}<0.05)$. This implies that family support greatly influenced coping with stroke in the study. Based on this, the null hypothesis is rejected and alternate hypothesis accepted.

Hypothesis two: There is no significant effect of financial support on coping with stroke by the medically ill patients (Table 3 ).

\begin{tabular}{|c|c|c|}
\hline Variables & Frequency $n=50$ & Percentage \% \\
\hline $\begin{array}{l}\text { Gender } \\
\text { Male } \\
\text { Female } \\
\text { Total }\end{array}$ & $\begin{array}{l}29 \\
21 \\
50\end{array}$ & $\begin{array}{c}58.0 \\
42.0 \\
100.0\end{array}$ \\
\hline \multicolumn{3}{|l|}{ Religion } \\
\hline $\begin{array}{l}\text { Christianity } \\
\text { Islam } \\
\text { Traditional }\end{array}$ & $\begin{array}{c}29 \\
20 \\
1\end{array}$ & $\begin{array}{c}58.0 \\
40.0 \\
2.0\end{array}$ \\
\hline \multicolumn{3}{|l|}{ Level of Education } \\
\hline $\begin{array}{l}\text { No formal education } \\
\text { Primary } \\
\text { Secondary } \\
\text { Tertiary } \\
\text { Others }\end{array}$ & $\begin{array}{c}4 \\
18 \\
20 \\
7 \\
10 \\
\end{array}$ & $\begin{array}{c}8.0 \\
36.0 \\
40.0 \\
14.0 \\
2.0\end{array}$ \\
\hline \multicolumn{3}{|l|}{ Occupation } \\
\hline $\begin{array}{l}\text { Farming } \\
\text { Petty Trading } \\
\text { Artisan } \\
\text { Civil Servant } \\
\text { Teaching } \\
\text { Pensioner } \\
\text { Others }\end{array}$ & $\begin{array}{c}8 \\
19 \\
2 \\
7 \\
5 \\
6 \\
3\end{array}$ & $\begin{array}{c}16.0 \\
38.0 \\
4.0 \\
14.0 \\
10.0 \\
12.0 \\
6.0\end{array}$ \\
\hline \multicolumn{3}{|l|}{ Monthly Income } \\
\hline $\begin{array}{l}\mathrm{N} 5,000 \\
\mathrm{~N} 6,000-\mathrm{N} 10,000 \\
\mathrm{~N} 11,000-\mathrm{N} 15,000 \\
\mathrm{~N} 16,000-20,000 \\
\mathrm{~N} 21,000-\mathrm{N} 30,000 \\
\mathrm{~N} 31,000-\mathrm{N} 40,000\end{array}$ & $\begin{array}{c}7 \\
3 \\
2 \\
10 \\
27 \\
1\end{array}$ & $\begin{array}{c}14.0 \\
6.0 \\
4.0 \\
20.0 \\
54.0 \\
2.0\end{array}$ \\
\hline \multicolumn{3}{|l|}{ Ethnic Origin } \\
\hline $\begin{array}{l}\text { Yoruba } \\
\text { Igbo } \\
\text { Niger-Delta }\end{array}$ & $\begin{array}{c}44 \\
5 \\
1\end{array}$ & $\begin{array}{c}88.0 \\
10.0 \\
2.0\end{array}$ \\
\hline
\end{tabular}

Table 1: Demographic characteristics of the respondents in terms of gender, religion, level of education, etc.

\begin{tabular}{|l|c|c|c|c|c|c|}
\hline Variable & Mean & Std. Dev. & N & R & P & Remark \\
\hline Family Support & 11.7000 & 2.0628 & 50 & 0.352 & 0.012 & Sig. \\
\hline Coping with Stroke & 7.9800 & 1.7319 & & & & \\
\hline
\end{tabular}

*Sig at 0.05 level

Table 2: Pearson product moment correlation showing the relationship between family supports and coping with stroke by the medically ill patients.

\begin{tabular}{|l|c|c|c|c|c|c|}
\hline Variable & Mean & Std. Dev. & N & R & P & Remark \\
\hline Financial Support & 8.5200 & 1.4602 & 50 & 0.658 & 0.000 & sig. \\
Coping with Stroke & 7.9800 & 1.7319 & & & & \\
\hline
\end{tabular}

*Sig at 0.05 level

Table 3: Pearson product moment correlation showing the relationship between financial supports and coping with stroke by the medically ill patients. 
Pearson Product Moment Correlation was used to determine the relationship between family support and coping with stroke by the medically ill patients. The results show that there was a significant effect of financial support on coping with stroke by the medically ill patients $(\mathrm{r}=0.658, \mathrm{~N}=50, \mathrm{p}<0.05)$. This implies that financial support did influence coping with stroke in the study. Based on this, the null hypothesis is rejected and alternate hypothesis accepted.

Hypothesis three: There is no significant effect of emotional support on coping with stroke by the medically ill patients (Table 4).

Pearson Product Moment Correlation was used to determine the relationship between emotional support and coping with stroke by the medically ill patients. The result from the above table shows that there was a significant relationship of emotional support on coping with stroke by the medically ill patients $(\mathrm{r}=0.402, \mathrm{~N}=50, \mathrm{p}<0.05)$. This implies that emotional support greatly influenced coping with stroke in the study, therefore the null hypothesis is rejected.

Hypothesis four: There is no significant effect of companionship support on coping with stroke by the medically ill patients (Table 5).

It is shown in the Pearson Product Moment Table above after the determination of companionship support and coping with stroke that there was a significant effect of companionship support on coping with stroke by the medically ill patients $(\mathrm{r}=0.654, \mathrm{~N}=50, \mathrm{p}<0.05)$. Companionship support did influence coping with stroke in the study. From result of the analysis, Null hypothesis is rejected while alternate hypothesis is accepted.

Hypothesis five: There is no significant joint effect of the

\begin{tabular}{|l|c|c|c|c|c|c|}
\hline Variable & Mean & Std. Dev. & N & R & P & Remark \\
\hline Emotional Support & 7.9600 & 2.6105 & 50 & 0.402 & 0.004 & Sig. \\
\hline Coping with Stroke & 7.9800 & 1.7319 & & & & \\
\hline
\end{tabular}

*Sig at 0.05 levels

Table 4: Pearson product moment correlation showing the relationship between emotional supports and coping with stroke by the medically ill patients.

\begin{tabular}{|l|c|c|c|c|c|c|}
\hline Variable & Mean & Std. Dev. & N & R & P & Remark \\
\hline Companionship Support & 12.1400 & 1.8953 & 50 & 0.654 & 0.000 & Sig. \\
\hline Coping with Stroke & 7.9800 & 1.7319 & & & & \\
\hline
\end{tabular}

${ }^{*}$ Sig at 0.05 levels

Table 5: Pearson product moment correlation showing the relationship between companionship supports and coping with stroke by the medically ill patients. independent variables (Family Support, Financial Support, Emotional Support and Companionship Support) on Coping with Stroke by the medically ill patients (Table 6a).

Analysis of Variance (ANOVA) was used to determine the joint effect of the independent variables (Family, Support, Financial Support, Emotional Support and Companionship Support) on coping with stroke. Table above shows that the joint effect of the independent variables (Family Support, Financial Support, Emotional Support and Companionship Support) to the prediction of Coping with Stroke was significant. The table also shows a coefficient of multiple correlation $\left(\mathrm{R}=0.847\right.$ and a multiple $\mathrm{R}^{2}$ of 0.717$)$. This means that $71.7 \%$ of the variance was accounted for by the predictor variables when taken together. The significance of the composite contribution was tested at $\mathrm{P}<0.05$. The above table also shows the analysis of variance (ANOVA) for the regression, which yielded an F-ratio of 28.445 (significant at 0.05 level). This implies that the joint contribution of the independent variables to the dependent variable was significant and that other variables not included in this model may have accounted for the remaining variance. Therefore, the null hypothesis was rejected while the alternate hypothesis was accepted (Table 6b).

Table above reveals the relative contribution of the independent variables to the dependent variable, expressed as beta weights, viz: Family Support $(\beta=-0.391, p<0.05)$, significant relationship existed; Financial Support $(\beta=0.418, p<0.05)$, significant relationship existed;

Emotional Support $(\beta=0.165, p<0.05)$ and significant relationship existed; Companionship Support $(\beta=0.7878, \quad \mathrm{p}<0.05)$; significant relationship existed respectively. Therefore, the above finding suggest that living with stroke requires joint effort of family support, financial support, emotional support and companionship support to help make the necessary changes to cope and adapt to stroke.

\section{Discussion of Findings}

The results obtained from testing the first hypothesis showed that there was a significant effect of family support on coping with stroke by medically ill patients $[20,21]$. This implies that giving family support to stroke patients elevates their level of coping with stroke. This finding is similar to the finding of Barrakat and Linney [22] that family support is one of the important factors in enhancing the potential ability of coping with stroke by medically ill patients and in reducing the severity and depressive symptoms effect of the daily strains experienced in coping with stroke. The study demonstrated that family support had

\begin{tabular}{|c|c|c|c|c|c|c|}
\hline $\mathbf{R}$ & \multicolumn{3}{|c|}{ R Square } & Adjusted R Square & \multicolumn{2}{|c|}{ Std. Error of the Estimate } \\
\hline 0.847 & \multicolumn{3}{|c|}{0.717} & 0.691 & \multicolumn{2}{|c|}{0.9621} \\
\hline \multicolumn{7}{|l|}{ ANOVA } \\
\hline Model & Sum of Squares & DF & Mean Square & $\mathrm{F}$ & Sig. & Remark \\
\hline $\begin{array}{l}\text { Regression } \\
\text { Residual } \\
\text { Total }\end{array}$ & $\begin{array}{c}105.324 \\
41.656 \\
146.980\end{array}$ & $\begin{array}{c}4 \\
45 \\
49\end{array}$ & $\begin{array}{c}26.331 \\
0.926\end{array}$ & 28.445 & 0.000 & Sig. \\
\hline
\end{tabular}

Table 6a: ANOVA showing the joint effect of the independent variables (Family, support, financial support, emotional support and companionship support) on coping with stroke by the medically ill patients.

\begin{tabular}{|l|c|c|c|c|}
\hline \multirow{2}{*}{ Model } & \multicolumn{2}{|c|}{ Unstandardized Coefficient } & Stand. Coefficient & Sig. \\
\cline { 2 - 5 } & B & Std. Error & Beta Contribution & T \\
\hline (Constant) & -1.970 & 1.057 & -1.864 & -2.866 \\
Family Support & -0.331 & 0.116 & -0.395 & 0.069 \\
Financial Support & 0.496 & 0.104 & 0.418 & 0.006 \\
Emotional Support & 0.109 & 0.056 & 0.000 & 1.970 \\
Companionship Support & 0.719 & 0.132 & 0.787 & 5.445 \\
\hline
\end{tabular}

Table 6b: Relative contribution of the independent variables (Family support, financial support, emotional support and companionship support) to the dependent variable (Coping with Stroke). 
significant effect on coping with stroke by the medically ill patients. The above finding also gives support to the finding of Kathleen et al. [23] that family structure-organization was associated with higher coping by stroke patients' and quality of life of stroke patients. It was also consistent with their increased family support being able to cope with stroke better than patients with low family support. The finding above tallies with the finding of Barrakat and Linney [22] that increased family social support relates to both higher coping by stroke patients psychological adjustment and higher clinical adjustment. Therefore, there is the need for effective programmes of intervention for family support for coping with stroke by medically ill patients.

The results obtained from the second hypothesis showed that there was a significant effect of financial support on coping with stroke by medically ill patients. This finding tally with the finding of Kathleen et al. [23] that increased financial support enables patients suffering from stroke to cope financially with physiotherapy sessions, likewise procurement of drugs, which in turn enables coping with stroke. The finding is also supported by the findings of Feroze et al. [24] that, the unique financial support by care-givers of patients suffering from stroke will enable such patients to reduce the difficulties surrounding coping with stroke. The findings is also in line with the findings of Feroze et al. [24] that, adequate financial support for patients suffering from stroke improves acceptance level in their adequate care and management [25] in his study also revealed that, financial support is important to increase a sense of hope for patients suffering from stroke. The results is also in accordance with the findings of Taylor et al. [25] that, lack of financial support for patients suffering from stroke have led to poor management of patients in low medium countries attending clinics, due to inability to procure drugs and other treatments plans. The same study also revealed that, most families of patients suffering from stroke are faced with economic challenge which makes it difficult for them to have access to healthcare even at the cheapest price. In another study conducted by Barrakat and Linney [22] found that, supports from International Non-Governmental Organisations and Government institutions has greatly improved the management that several stroke patients receive through financial aid to buy medications and accessing prompt treatment from qualified personnel. Furthermore, Feroze et al. [24] found that, financial support from family members and other significant social network improves consistent intake of medication and increased access to treatment of stroke patients attending hospitals

The results of the third hypothesis indicated that there was a significant effect of emotional support on coping with stroke by the medically ill patients. Emotional support did influence coping with stroke in the study. This finding supports the finding Carlsson et al. [20] that perceived emotional support moderated the relationship between functional status and depressive symptoms by medically ill patients coping with stroke. The study highlighted the importance of emotional support as a potential catalyst for coping with stroke by the medically ill patients. The findings is also accordance with the findings of Feroze et al. [24] that, improving emotional support for medically ill patients suffering from stroke reduces the rate of stressors towards achieving an improved coping with stroke. The study suggested that practitioners and families can mediate negative self-image in stroke patients by intervening to increase the social support network thereby enhancing their adaptation, coping and recovery from stroke. The finding is also in accordance with findings of Carlsson et al. [20] that, emotional support through counselling services for patients and caregivers reduces their stressful experiences in the care and management of stroke. Chesla et al. [21] in their study also observed that, emotional support is important in the reduction and prevention of stressors in care of stroke.
The results obtained from testing the fourth hypothesis showed that there was a significant effect of companionship support on patients coping with stroke. The finding support the finding of Carlsson et al. [20] that companionship support was associated with higher stroke patients' quality of life. The above finding also supports the finding of Chesla et al. [21] that companionship support has been found to promote psychological adjustment in conditions with stroke and chronic high stress like cancer and coronary artery disease. It is evident therefore that people with low companionship support report more sub-clinical symptoms of depression and anxiety than do people with high companionship support. The findings is supported with the findings of Barrakat and Linney [22] that, with companionship support from families there is evident improvement in coping with stroke by the medically ill patients, the study also revealed that lack of companionship support from family members tends to create some degree of internal or external stigma for patients suffering from stroke which significantly affects coping. Additionally, the findings also supports the finding of Owolabi [19] that companionship support from both immediate and extended family members improves self-adjustment of patients suffering from stroke. The same study was conducted by Chesla et al. [21] and observed that, improving positive companionship support increases the coping of patients suffering from stroke.

Results obtained from testing the fifth hypothesis revealed that the joint effect of the independent variables (Family Support, Financial Support, Emotional Support and Companionship Support) on the dependent variable (Coping with Stroke) was significant. The above finding is consistent with the finding of Kathleen et al. [23] that social support, which is defined as the comfort, assistance and/or information one receives through formal or informal contacts with individuals or groups, has been linked to coping with stroke. The finding is in consonance with the finding of Talabi [12] that social support has an overall beneficial effect for medically ill patients having stroke, regardless of the number of stressful events to which he or she is exposed. Social support is associated with increased psychological well-being in the workplace and in response to important life events. In stressful times, social support helps people reduce psychological distress (e.g. anxiety or depression). The finding is also in accordance with the findings of Taylor et al. [25] that social support can simultaneously function as a problem-focused (e.g. receiving tangible information that helps resolve an issue) and emotion-focused coping strategy (e.g. used to regulate emotional responses that arise from coping with stroke. The above finding corroborates with the finding of Folkman and Lazarus [26] that social support has been found to promote psychological adjustment in conditions with chronic high stress like stroke. Additionally, social support has been associated with various acute and chronic pain variables. People with low social support report more sub-clinical symptoms of depression and anxiety than do people with high social support. People with low social support have higher rates of coping with stroke than those with low social support. These include post-traumatic stress disorder, panic disorder, social phobia, major depressive disorder, dysthymic disorder and eating disorders. In addition, people with low support have more suicidal ideation and more alcohol and (illicit and prescription) drug problems. Religious coping has especially been shown to correlate positively with positive psychological adjustment to stroke. Many people with stroke have a low perceived susceptibility which can be explained as a sense of low social support about their illness. Their perceived severity of the illness is affected by those to whom they compare themselves too, often resulting in people believing their illness is not severe enough to seek support. Due to poor past experiences or educated speculation, the perception 
of benefits for seeking social support is relatively low. The number of perceived barriers towards seeking social support often prevents people with stroke from getting the support they need to better cope with their illness.

Finally, the results obtained from testing the sixth hypothesis showed a relative contribution of each of the independent variables (family support, financial support, emotional support and companionship Support) to the dependent variable (coping with stroke by the medically ill patients). This finding support the finding of Langford et al. [27] that social support (family, financial, emotional and companionship support) enhance coping with stroke as well as physical and mental health. The findings also in line with the findings of Loucks et al. [28], which states that examined moderating effects of social support on the relationship of stressors to caregivers' psychological adaptation in a sample of caregivers of patients with stroke. The findings from the study indicated that social support and family support buffered the potential detrimental effects of caring for stroke patients perceived as hard to manage. The result of the findings is also in accordance with findings of Kathleen et al. [29] that assessed the relationship between social support and health related quality of life in both non-stroke patients and patients suffering stroke. The findings from the research showed that social support was significantly and positively related to health related quality of lives for both groups of patients. Social support from various sources was positively related to the families of ill patients, health related quality of lives as well as their physical, psychological and social well-being and self-concept.

Based on the above finding, it becomes imperative that adequate social support be given to the stroke patients to enable them cope, adjust and recover quickly from their medical illness. To this end family member, friends, co-workers, neighbors and other significant persons in the life of the stroke patients should give them adequate emotional support, financial support, companionship support so as to help them cope successfully and recover quickly from their medical illness. The health care-givers should also give maximum support to the stroke patients at admission, during and after being discharged from the hospital. These will help in instilling hope in them and as well improve the quality of their life.

\section{Conclusion}

Based on the literature review and on the findings of the study, it can be concluded that stroke is a progressive disease condition and the disturbances it brings are also progressive. Therefore, any intervention has to be tailored to the progress of the disease itself, with the individual's level of physical, psychological and social functioning as the central focus. The concurrent coping with stroke demand cognitive effort from the patient. Social support intervention is best started as early (at diagnosis) and demands continuous effort.

\section{1) Recommendation}

2) Social support from family members and caregivers especially to patients suffering from stroke as mentioned in the study is of great importance to improve their health. Family and care givers of stroke patients should always remember that low social support has a negative response to the health stroke patients. It is also recommended that care givers should be optimistic seeing the brighter side of patient's life.

3) Mental health clinicians should assist in increasing emotional support from family of patients with stroke by providing programmes that would increase caregivers' experience of social support. They should also introduce programmes that educate families and care givers about how to develop more positive social support behaviors.

4) The medical social workers, nurses and other health care givers should improve their scope of knowledge and skills to have a greater understanding of how personal factors impact the health of medically ill patients suffering from stroke. This knowledge would support physicians as well as psychologists in helping patients identify factors that influence their ways of coping and advice families and caregivers to think strategically about how their relationships with patient can support them emotionally.

5) Medical practitioners and social workers should learn to display greater empathy whenever they come in contact with stroke patients. Empathy should be emphasized as an important tool whenever interventions for stroke patients are carried out. This, in turn, putting them in a better position to provide the support and help needed.

6) Furthermore the policy makers and government agencies should provide policy services that address social support and health needs of patients with stroke.

\section{References}

1. Donnan GA, Fisher M, Macleod M, Davis SM (2008) Effectiveness of stroke. BMJ 371: 1612-1623.

2. Kidwell CS, Warach S (2003) Acute ischemic cerebrovascular syndrome Diagnostic criteria. Stroke 34: 2995-2998.

3. Guercini F, Acciarresi M, Agnelli G, Paciaroni M (2008) Cryptogenic stroke: Time to determine aetiology. J Thromb Haemost 6: 549-554.

4. Bamford J, Sandercock P, Dennis M, Burn J, Warlow C (1991) Classification and natural history of clinically identifiable subtypes of cerebral infarction. Lancet 337: 1521-1526.

5. Osterweil N (2013) Methamphetamine induced ischemic strokes. Barnhart R (Edr.) The Barnhart concise dictionary of etymology: Overview of the current literature. 89: 135-241.

6. Murray ED, Buttner N, Price BH (2012) Application of Health promotion and health behaviour. US department of health and human services, National Institutes of Health.

7. Coffey CE, Cummings JL, Sergio RR (2000) Stroke: The American Psychiatric Press Textbook of Geriatric Neuropsychiatry (Second Edition.), Washington DC. Am J Psychiatr 30: 601-617.

8. Tom A, Schweizer R, Loch M (2014) The behavioural consequences of stroke. Int J Health Sci 15: 119-133.

9. Mackenzie C (2011) Dysarthria in stroke: A narrative review of its description and the outcome of intervention. Int J Speech Lang Pathol 13: 125-136.

10. Senelick RC, Peter W, Dougherty K (1994) Living with stroke. J Adolesc Health J Adolesc Med 56: 554-673.

11. Gallant W, Dorn C, Levy R, Pickering TG (2001) Social support in social interaction: A moderator of cardiovascular reactivity. J Psychosom Med 54: 324-336.

12. Talabi OA (2003) A 3 year review of neurologic admissions in University College Hospital Ibadan, Nigeria. West African Journal of Medicine 22: 50-71.

13. Peters GO, Hamzat TK (2008) Activity, participation and quality of life after stroke: A 6 month follow-up of community-dwelling Nigerian stroke survivors. Indian J Physiother Occup Ther.

14. Pompili M, Venturini P, Campi S, Seretti ME, Montebovi F, Lamis DA (2012) Do stroke patients have an increased risk of developing suicidal ideation or dying by suicide. J Adv Nurs 8: 551-776.

15. Glass TA, Matchar DB, Belyea M, Feussner JR (1993) Impact of social support on outcome in first stroke. Journal of Haemorrhagic Stroke 24: 64-70. 
Citation: Blessing M, Oluwagbemiga O (2017) Effectiveness of Social Support in Coping with Stroke by Medically III Patient in Ibadan. Int J Neurorehabilitation 4: 281. doi: 10.4172/2376-0281.1000281

16. Huang CY, Hsu MC, Hsu SP, Cheng PC (2010) Mediating roles of socia support on post-stroke depression and quality of life in patients with ischemic stroke. J Clin Nurs 19: 52-62.

17. Salter K, Foley N, Teasell R (2010) Social support interventions and mood status post stroke: A review. Int J Nurs Stud 47: 616-625.

18. Glymour MM, Weuve J, Fay ME, Glass T, Berkman LF (2008) Social ties and cognitive recovery after stroke: Does social integration promote cognitive resilience. J Neuroepidemiol 31:10-20.

19. Owolabi MO (2008) Determinants of health-related quality of life in Nigerian stroke survivors. Trans R Soc Trop Med Hyg 102: 19-25.

20. Carlsson GE, Forsberg-Warleb YG, Möller A, Blomstrand C (2008) Comparison of life satisfaction within couples one year after a partner's stroke. J Rehabil Med 39: 219-224.

21. Chesla E, Cohen S, Miller Gregory E (2004) How low socioeconomic status affects 2 year hormonal trajectories in children. J Psychol Sci 21: 31-37.

22. Barrakat M, Linney N (1992) Distinctions between social support concepts, measures and models. Am J Community Psychol 14: 413-445.
23. Kathleen R, Brisson C, Kawakami N, Houtman I, Bongers P, et al. (2010) An instrument for internationally comparative assessments of psychosocial job characteristics. J Occup Health Psychol 3: 322-355.

24. Feroze SB, Rucke MR, Dudenhausen J, Pincus-Knackstedt MK, Klapp BF, et al. (2006) Social support during pregnancy: Effects on maternal depressive symptoms, smoking and pregnancy outcome. J Hum Reprod 22: 869-877.

25. Taylor SE, Sherman DK, Kim HS, Jarcho J, Takagi K, et al. (2003) Culture and social support: Who seeks it and why? J Pers Soc Psychol 87: 354-362.

26. Folkman S, Lazarus RS (2001) Coping and emotion. Stress and coping: An anthology. Columbia University Press.

27. Langford CPH, Bowsher J, Maloney JP, Lillis PP (1997) Social support: a conceptual analysis. J Adv Nurs 25: 95-100.

28. Loucks EB, Berkman LF, Gruenewald TL, Seeman TE (2006) Relation of socia integration to inflammatory marker concentrations in men and women 70-79 years. Am J Cardiol 97: 1010-1016.

29. Kathleen R, Brisson C, Kawakami N, Houtman I, Bongers P, et al. (2010) An instrument for internationally comparative assessments of psychosocial job characteristics. J Occup Health Psychol. 